\title{
Access to and use of the Wienerwald Biosphere Reserve by Turkish and Chinese people living in Austria - implications for planning
}

\author{
Anna Höglhammer, Andreas Muhar \& Patricia Stokowski
}

Keywords: accessibility, outdoor recreation participation, immigrant communities, qualitative research methods, Biosphere Park, ethnicity

Abstract
Peri-urban protected areas such as the UNESCO Wienerwald Biosphere Reserve
(WWBR) offer important recreational opportunities. However, access has been shown
to be restricted for certain groups, and immigrants from non-western countries
especially are found to be under-represented as user groups. This paper presents re-
search findings from a transdisciplinary pilot study undertaken in Vienna and Lower
Austria investigating the importance of the WWBR in the leisure lives of immigrants
(focusing on Turkish and Chinese immigrants), and barriers that hinder people
from using the WWBR. A qualitative research design was adopted, and in total 80
interviews (40 from each community) were obtained. Results show a strong apprecia-
tion for natural areas and a high awareness among all participants of the positive
impacts for health and well-being. The social environment has a strong influence on
outdoor recreation participation, and ethnic-cultural and community-related aspects
affecting access were identified. The study shows that planning authorities face chal-
lenges in providing adequate information, especially concerning access and on-site
use. Gatekeepers are needed to remove access barriers based on fears and insecuri-
ties. Other challenges for planning authorities are also addressed, and recommen-
dations for managerial action are presented.

Profile

Protected area

Wienerwald Biosphere

Reserve

Mountain range

Alps

Country

Austria

\section{Introduction}

Protected areas such as peri-urban forests are perceived by the public as being open to everyone, but researchers have shown access barriers to recreational areas in many western countries for non-western immigrants (Aizlewood et al. 2006; Buijs et al. 2009; Gentin 2011; Jay et al. 2012; Kloek et al. 2013). As natural areas have important functions as spaces outside the urban fabric for recreation, relaxation and the promotion of active lifestyles (Nutsford et al. 2013; O’Brien \& Morris 2013; Swanwick et al. 2003), reducing barriers has become a major concern for public authorities and park administrations. Researchers have shown that visits to natural areas can help to reduce health risks such as cardiovascular diseases, obesity, health issues related to increasingly sedentary lifestyles, and stressrelated mental health problems (Barton \& Pretty 2010; Bauer 2010; Guite et al. 2006; Hartig 2008). Further, because such areas are usually publicly funded, providing equal access for all groups of society becomes a matter of environmental and social justice (Byrne et al. 2009; Jay et al. 2012).

\section{Immigration and accessibility to outdoor} recreation

Immigrants from non-western countries are disadvantaged in several public domains, including education (Schnell 2014), access to public areas and health (Statistik Austria 2014), leisure activities (Spracklen

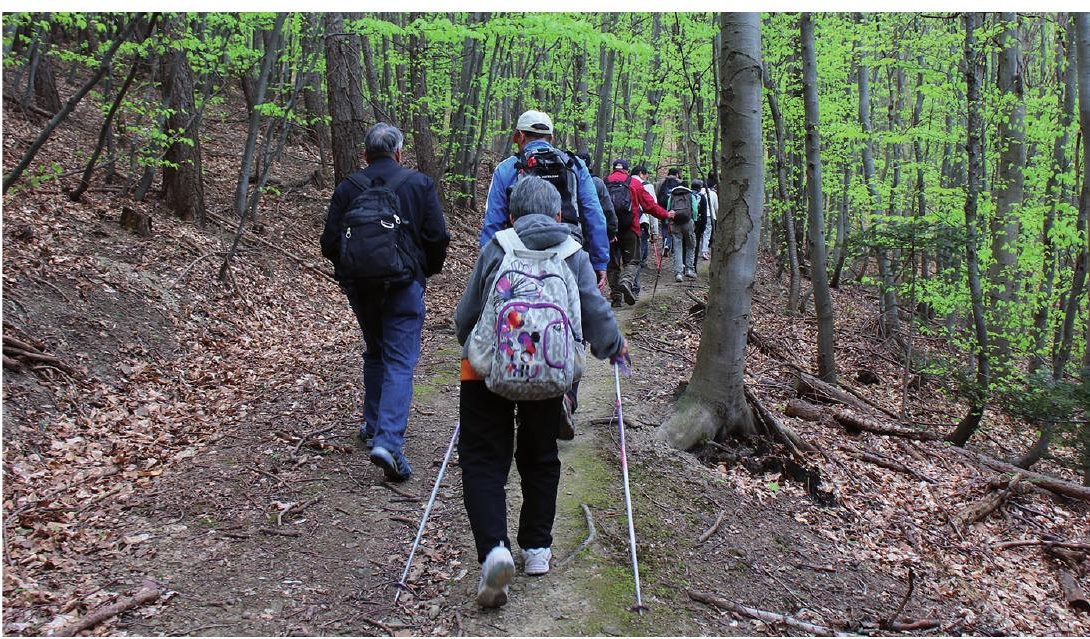

Figure 1 - Chinese hiking group in the Wienerwald Biosphere Reserve. (C) A. Höglhammer

2013), and the labour market (EUMC 2006; Statistik Austria 2014). Specific constraints on immigrants' access to outdoor recreation have been noted in the literature (Aizlewood et al. 2006; Byrne et al. 2009; Floyd et al. 1993; Gentin 2011; Kloek et al. 2013; Morris \& O’Brien 2011), and researchers have studied how ethnic-cultural and socio-economic backgrounds influence the participation of immigrants in outdoor recreation (Gentin 2011; Jay et al. 2012; Kloek et al. 2013). In particular, the distribution of public green spaces and inequalities in access to housing affect access to 


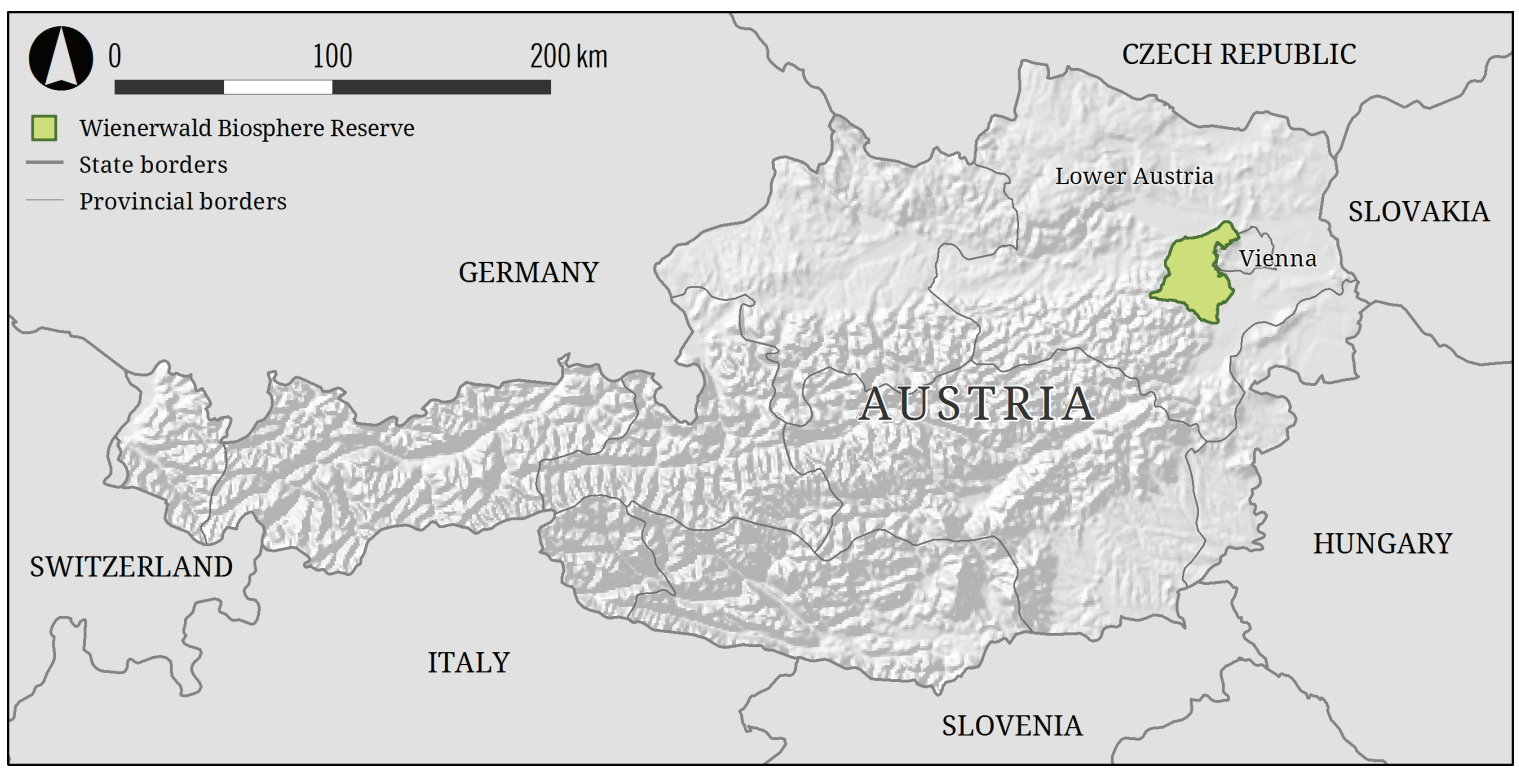

Figure 2 - The Location of the Wienerwald Biosphere Reserve in Vienna and Lower Austria. Data base: SRTM-DEM

public green spaces in cities for immigrants. Furthermore, the immigration process itself has been identified as adversely affecting people in carrying out their preferred leisure activities (Höglhammer et al. 2015b; Stodolska 2000). Public opinion in general regarding immigrants, is particularly relevant with respect to individuals' feelings of acceptance, social embeddedness or social integration (Jay et al. 2012).

Ethnic-cultural factors also explain differences in recreational behaviour: cultural norms and values foster different landscape preferences and preferred leisure activities (Aizlewood et al. 2006; Höglhammer et al. 2015b; Kloek et al. 2013). Studies show preferences among immigrants from non-western countries for socializing in often-large groups, and for food-related activities (Jay \& Schraml 2009; Kloek et al. 2013). This is frequently seen as behaviour that is different from that of the autochthonous populations in Western European countries, for whom outdoor recreation is more often associated with solitary visits or visits in small groups (Kloek et al. 2013, p. 125), and more individualistic forms of physical activity such as hiking or mountain biking.

The project context

The Wienerwald Biosphere Reserve (WWBR) is a large UNESCO Biosphere Reserve at the eastern extremity of the Alps, located in the Austrian federal provinces of Vienna and Lower Austria (see Figure 2). The mostly mountainous forest landscape is a biodiversity hotspot and serves as an important recreation area for the Vienna conurbation. The park management has noted the under-representation of people from certain ethnic communities. In order to investigate barriers that hinder some groups from using the WWBR, the UNESCO Man and Biosphere Programme of the Austrian Academy of Sciences commissioned a research project entitled Attitudes and satis- faction regarding the Wienerwald Biosphere Park: A pilot study towards the integrative function of peri-urban protected areas (Höglhammer et al. 2015a).

The primary aim of the pilot study was to understand the importance of the WWBR in the leisure lives of immigrants and to identify barriers to use. The focus was on people from the Turkish and Chinese communities in Vienna and Lower Austria, the two largest groups of non-western immigrants (Statistik Austria 2014), with varying cultural and religious backgrounds. An exploratory and transdisciplinary research design was adopted which took into account the perspectives and practical knowledge of different stakeholders. In the first research phase, stakeholders from different fields of expertise (forestry/management, integration / diversity, health / exercise and Chinese/Turkish cultural organizations) were interviewed to gain practical knowledge about migration and outdoor recreation, and to identify research fields relevant for the stakeholders. During this stage, it became clear that the influence of the migration process itself and the public attitude towards foreigners both play major roles concerning integrational attempts. Furthermore, the focus of migration and integration attempts is mainly on language and work, with little attention given to leisure activities.

Based on the results of the stakeholder interviews, an interview guideline was developed focusing on: (1) the understandings and importance of leisure, and favourite leisure activities; (2) the importance of natural areas for leisure activities and what kind of natural areas are used; (3) knowledge and importance of the WWBR for people's leisure; (4) life before immigration; (5) social and demographic data.

Findings from the interviews with stakeholders and results concerning the experiences and meanings of leisure for immigrants have already been presented elsewhere (Höglhammer et al. 2015a). In the current 
paper, we specifically address the question of what importance people from the Turkish and the Chinese communities give to nature and nature-based settings such as the WWBR, and how they use this particular large protected area for leisure purposes. The findings form the basis for recommending management measures to the park administration.

\section{Methods}

\section{Qualitative interviews}

To overcome language barriers, two bilingual interviewers were employed to conduct qualitative interviews with adult individuals (min. age 18 years) from the two immigrant communities. Interviewees were recruited via relevant cultural associations, as well as by direct contact in parks and leisure settings, and in Turkish and Chinese shops and restaurants. This procedure ensured a sample that was diverse in age, gender, educational background and occupation (see Tables 1 and 2). In total, 80 individuals (40 from each community) were interviewed. About $80 \%$ of the sample were first-generation immigrants; in the Turkish community, 12 interviewees were second generation; in the Chinese community, we were able to recruit only three second-generation immigrants.

\section{Data analysis}

Thematic coding of the transcribed and translated interviews was performed using the software atlas.ti. To ensure code congruence, interview extracts that were coded by the bilingual interviewers were compared with material coded by the researchers. After checking the code congruence, all transcripts were coded by two researchers and the bilingual interviewers. An inductive coding approach was applied in which researchers and bilingual interviewers coded and discussed the data, generating descriptive codes (Miles \& Huberman 1994). A thematic analysis was then conducted, codes were categorized in several iterations of analysis, and finally were summarized in four themes relevant for the research question: outdoor recreation, the Wienerwald, leisure activities and barriers. This process helped to give us a first impression about major issues identified by the interviewees. It also helped to identify text segments important for data interpretation. Further data interpretation was a collaborative process of ongoing writing and discussion among members of the research team. Consistency was ensured by several researchers being involved in the data interpretation process.

\section{Results}

\section{Knowledge and use of the WWBR}

While some interviewees from both communities did not know the area of the Wienerwald at all, the majority named or described locations within the area that they had visited at least once. However, the use
Table 1- Age of interviewees by gender.

\begin{tabular}{|l|l|l|l|l|}
\hline Age & $\begin{array}{l}\text { Turkish } \\
\text { (f) }\end{array}$ & $\begin{array}{l}\text { Chinese } \\
(\mathbf{f})\end{array}$ & $\begin{array}{l}\text { Turkish } \\
(\mathbf{m})\end{array}$ & $\begin{array}{l}\text { Chinese } \\
(\mathbf{m})\end{array}$ \\
\cline { 2 - 5 } & $\mathrm{n}=20$ & $\mathrm{n}=24$ & $\mathrm{n}=20$ & $\mathrm{n}=16$ \\
\hline $20-30$ & 4 & 9 & 5 & 6 \\
\hline $30-40$ & 10 & 3 & 4 & 3 \\
\hline $40-50$ & 1 & 5 & 5 & 3 \\
\hline $50-60$ & 2 & 3 & 4 & 2 \\
\hline $60-70$ & 2 & 2 & 2 & - \\
\hline Over 70 & 1 & 2 & - & 2 \\
\hline
\end{tabular}

Table 2 -Educational background of the interviewees by gender.

\begin{tabular}{|l|r|l|l|l|}
\hline $\begin{array}{l}\text { Educational Back- } \\
\text { ground (highest level } \\
\text { attained) }\end{array}$ & $\begin{array}{l}\text { Turkish } \\
\text { (f) }\end{array}$ & $\begin{array}{l}\text { Chinese } \\
\text { (f) }\end{array}$ & $\begin{array}{l}\text { Turkish } \\
\text { (m) }\end{array}$ & $\begin{array}{l}\text { Chinese } \\
\text { (m) }\end{array}$ \\
\cline { 2 - 5 } & $\mathrm{n}=20$ & $\mathrm{n}=24$ & $\mathrm{n}=20$ & $\mathrm{n}=16$ \\
\hline Primary education & 6 & 1 & 7 & 5 \\
\hline $\begin{array}{l}1-2 \text { years vocational } \\
\text { education or training } \\
\text { programme }\end{array}$ & 4 & 2 & 4 & 1 \\
\hline High school education & 1 & 7 & 4 & 3 \\
\hline $\begin{array}{l}\text { University degree (first, or } \\
\text { Batchelor's, degree) }\end{array}$ & 3 & 8 & 2 & 4 \\
\hline $\begin{array}{l}\text { Master's or professional } \\
\text { degree programme }\end{array}$ & 3 & 3 & 2 & 0 \\
\hline $\begin{array}{l}\text { MD, PhD, JD or other } \\
\text { higher degree }\end{array}$ & 1 & 0 & 0 & 1 \\
\hline Unknown & 2 & 4 & 1 & 1 \\
\hline
\end{tabular}

level was generally very low. The concept of a Biosphere Park was completely unknown to all interviewees, while knowledge about use rights, use restrictions (e.g. picking fruits and mushrooms, collecting medical plants) and management regimes was minimal.

The influence of the social environment on park utilization and outdoor recreation participation

For interviewees from both communities, outdoor recreation is organized collectively - in a group, via an organization, or with the family. Thus, a person's level of information about outdoor recreation activities is dependent largely on his or her social environment. Most interviewees stated that they had been informed by other people or by institutions (school, associations, interest groups) about natural areas or places to visit in the Wienerwald. Two interviewees had looked up information on their own, using a map, to find out about green areas around Vienna. For the majority, the main criterion associated with initiating visits to an unknown forest place was being accompanied by a person who was informed and would be guiding the way.

For interviewees in this study, not only access to but also the use of larger recreational areas - especially forests - were related to a collective rather than an individual experience. Thus, interviewees visited natural areas in the company of others. The groups of visitors were not necessarily large, but individual visits to natural areas were rarely mentioned. This was especially the case for outdoor recreational activities such as hiking. Diverse reasons for not going alone to the forest were mentioned (such as enjoyment / fun, motivation or guidance), but anxiety was the most prominent one. 
Importance of nature and outdoor recreation participation

In general, interviewees revealed a high appreciation for nature, and most of those participating in the study were aware of the health benefits of being out in nature. Health can be a motivational factor for visiting natural areas, but health problems, especially restricted mobility, can constitute a barrier. Interviewees often spoke about taking walks in natural areas, but the term biking was rarely used. The phrase taking a walk was often used to describe quite a long time spent in the forest, though walking was not perceived as a sport by these participants.

\section{Turkish community}

Nearly all interviewees were aware of the significant benefits that nature has for health and wellbeing, describing experiences in nature as very important for these reasons. However, being in nature was often not connected to physical activity, such as hiking, but was linked to passive activities such as looking at the scenery, drinking tea or having a picnic.

Nature was often associated with feelings of freedom and mental relaxation. Other important aspects of visits to natural areas were fresh air, recreation, silence and pleasant scenery. Interviewees stated that they felt comfortable in natural areas and would like to visit them more often. Four interviewees specifically emphasized the importance of being in natural areas as a respite from living in an urban environment.

Interviewees underlined the value of natural areas for relaxation and recovery and stated that natural spaces are "places where one can find inner peace". Some interviewees also described how just looking at the scenery or plants and watching animals supports them in relaxing and relieving stress. Another factor mentioned was that the openness or vastness of the natural environment brings relief to and clears the mind.

\section{Chinese community}

Interviewees from the Chinese community also had a great awareness of the benefits of being in natural areas, and for them being in nature on a regular basis was very important. The Chinese interviewees reported more often than the Turkish interviewees that they actively participated in outdoor recreation (mainly hiking). A privately organized hiking group was discovered during the research project; it was led by an older, first-generation immigrant with no German-language skills who had explored hiking routes in the WWBR by himself. Hiking trips for this group are organized three times per week, and many Chinese interviewees were aware of these opportunities. Health was the main reason given for going to the forest to hike, but social aspects of hiking were also mentioned frequently. Five participants indicated that they did not enjoy being in natural areas because of allergies, and so they generally avoided outdoor recreation.

\section{Ethnic-cultural and community influences on outdoor recreation participation}

\section{Turkish community}

Barbecuing or picnicking were frequently mentioned leisure activities in interviews with people from the Turkish community. Such outdoor eating was often associated with cultural heritage by the interviewees, indicating a strong cultural identification. Interviewees often used wordings such as "we," "us Turks",

Table 3 - Challenges for planning authorities, recommendations for managerial actions and external influences. Wienerwald Biosphere Reserve WWBR

\begin{tabular}{|c|c|c|}
\hline Challenges for planning & Recommendations for managerial action & External influences \\
\hline $\begin{array}{l}\text { Lack of awareness of use } \\
\text { of the WWBR; user } \\
\text { preferences }\end{array}$ & $\begin{array}{l}\text { - community-specific information about possible uses of the WWBR } \\
\text { - involving cultural associations in development of activities and measures } \\
\text { through workshops (participative planning approach) } \\
\text { - bilingual information, and guided tours specifically for the target group } \\
\text { - more extensive information on access, orientation, routes, maps } \\
\text { - advice on equipment } \\
\text { - health and safety information (ticks or other specific flora and fauna) }\end{array}$ & $\begin{array}{l}\text { - more cultural/ethnic diversity among man- } \\
\text { agement staff }\end{array}$ \\
\hline $\begin{array}{l}\text { Raising awareness about } \\
\text { the positive impacts on } \\
\text { health and wellbeing }\end{array}$ & $\begin{array}{l}\text { - promoting possibilities for soft physical activity (e.g., taking walks in nature) } \\
\text { - information concerning accessibility for people with disabilities } \\
\text { - promoting the WWBR as a peri-urban natural area for recreation and } \\
\text { relaxation and other health-related benefits } \\
\text { - work with health providers in the cultural communities to distribute } \\
\text { information about outdoor opportunities }\end{array}$ & \\
\hline Perceived access barriers & $\begin{array}{l}\text { - gatekeeper (ideally from the immigrant community) } \\
\text { - ethnically diverse guides }\end{array}$ & $\begin{array}{l}\text { - positive attitude towards foreigners, immi- } \\
\text { grants, other cultures }\end{array}$ \\
\hline $\begin{array}{l}\text { Lack of integrated infor- } \\
\text { mation infrastructure }\end{array}$ & $\begin{array}{l}\text { - providing areas for barbecuing / picnicking or cultural/religious festivities } \\
\text { and for family recreation } \\
\text { - communicate a code of conduct if expected (use of barbecues, waste, etc.) } \\
\text { - provide information in diverse languages }\end{array}$ & $\begin{array}{l}\text { - mutual understanding regarding differences } \\
\text { in leisure activity preferences } \\
\text { - positive opinion about the cultural diversity } \\
\text { of society } \\
\text { - awareness of social justice regarding public } \\
\text { infrastructure }\end{array}$ \\
\hline $\begin{array}{l}\text { Attachment to the } \\
\text { community }\end{array}$ & $\begin{array}{l}\text { - addressing the immigrant community using appropriate forms of } \\
\text { communication } \\
\text { - offering activities for larger groups } \\
\text { - addressing individuals from the communities in other contexts - } \\
\text { not reducing their identities to their migration background }\end{array}$ & - public tolerance towards cultural gatherings \\
\hline
\end{tabular}


"Turkish people". Barbecuing is enjoyed mainly with family members and friends or relatives, and occasionally in larger groups (most often organized by cultural associations). Interviewees also sometimes just went for a picnic in a natural space with their partner. The presence of other Turkish people at barbecue spots was mentioned as an important, positive factor.

Interviews also showed that barbecue spots in natural areas in Vienna serve several functions and are especially suitable for families. In these locations, perceived safety is very high as such places offer the possibility for children's play and recreation.

The use of urban green spaces for barbecuing is strongly connected with the socio-economic status of a person. Interviewees who owned private green spaces (gardens) usually reported that they used public natural spaces less often for barbecuing and did not feel the need to go to larger natural areas.

Thus, interviews showed the importance of attachment to community, but also of socio-spatial influences regarding the suitability of places for family recreation (places for children's play, safety issues, space for larger groups, and transport connections).

\section{Chinese community}

In interviews with people from the Chinese community, a strong difference between life before and life after migration was noted. Four interviewees stated that they had avoided outdoor activities in China, mainly because of air and environmental pollution; some described having heavy workloads that did not leave time for leisure and outdoor recreation. The different climate was often mentioned as a barrier to going outdoors in China, as were access restrictions, the small number of places for outdoor recreation, or the overcrowding of local outdoor recreation areas. Therefore, participating in outdoor recreation had not been a habit for those interviewees.

Interviewees now enjoy the outdoors in Austria, and access to natural sites is mainly facilitated through a gatekeeper (a hiking group leader, family or friends). These interviewees pointed to several positive aspects of recreational areas in Austria that supported their decisions to participate in outdoor recreation. These include perceptions of safety, the enjoyable qualities of the natural environment, and the generally good outdoor recreation infrastructure. Interviewees also stated that they enjoy outdoor recreation in Austria because it is a way to discover new places and things.

A small number of interviewees stated that they used to go hiking a lot in their childhood in China but had stopped after migrating to Austria due to a lack of knowledge about outdoor recreation possibilities or a heavier workload after migrating.

For the Chinese participants, attachment to their own community was also very important, but the strong influences of the migration process itself were also identified. The influence of the social environment was a more important driver for outdoor recrea- tion participation than an individual's personal interests or motivations.

\section{Discussion and conclusions for planning}

Our results show that in both the Turkish and the Chinese immigrant communities in Vienna, people are very aware of the importance of nature for health and wellbeing, and most have already visited places in the WWBR. Our study identified three main motivations for using natural spaces, which can simultaneously constitute barriers to accessing those areas: (1) the social environment, (2) personal health and wellbeing, and (3) cultural heritage / immigration processes.

The social environment had a very strong influence on outdoor recreation participation, although visits to the forest did not necessarily involve large groups of people or food-related activities (Jay \& Schraml 2009; Kloek et al. 2013). Even if people preferred not to visit the forest alone (mainly because of fear), outdoor recreational activities were not dependent on participation by large groups. Large groups were more common when people gathered for festivities organized by cultural associations.

Barbecuing was a very prominent activity in the Turkish community, and interviewees explained that this was strongly associated with cultural traditions and heritage. According to Gentin (2011), barbecuing is an activity that assists in creating community identity, especially because of the presence of other members of the community when using public barbecue spaces. Our results also show that (as with other ethnic groups and the mainstream population) using public spaces for barbecuing seems to be related to a person's socio-economic status. Furthermore, social recreation spaces often offer suitable areas for family recreation and their perceived safety is very high. It must, however, be noted that barbecuing is a topic that is heavily laden with stereotypes. Barbecuing may in reality be practised less often than the interviews would suggest (Kloek et al. 2013).

The complexity of investigating how cultural backgrounds influence the importance given to outdoor recreation was especially noted in interviews with people from the Chinese community, where strong intracultural differences in recreational use preferences were identified. Immigrants' experiences and influences after migrating to Austria were highly significant in determining whether they became involved in outdoor recreation activities or not. The role of a gatekeeper or others who engaged in activities (often in groups) was very important for personal decisions about participating in recreation. Rarely did people feel capable of going outdoors into a new environment by themselves. To ensure sustainable and independent recreational use of natural areas, gatekeepers must provide recreation novices with the necessary information and knowledge to develop skills and self-confidence when visiting those sites. 
Our study results suggest several challenges for planning authorities; they also illustrate the importance of external influences on access to and use of natural areas (see Table 3).

The fact that people did not know about the Biosphere Park or the WWBR indicates that immigrant communities are not addressed by the information that is currently available or the communication strategies undertaken by the park management. Targetgroup-specific information and communication tools are needed to attract members of these communities as users. For example, interviewees rarely used the term hiking when talking about their outdoor recreation activities, which they categorized, rather, as taking a moderate walk; they reserved the term biking for a demanding physical activity. Yet several sites in the WWBR classified by the park authorities as suitable for biking are suitable for shorter walks or trips. Being more sensitive in this respect could be a way for park managers to attract people from the two immigrant communities. The same could be said for health issues restricting the use of the WWBR. Although several offers for people with restricted mobility already exist in the WWBR (see e. g. https://www.bpww.at/en/ node/1019), immigrant groups are not specifically addressed (e. g. by providing multilingual information).

Our results show that it is crucial to address the whole community (cultural organizations, gatekeepers from the community, etc.), although addressing people solely within their specific ethnic contexts neglects the diversity of other personally-lived identities (Kloek et al. 2013) and may reinforce stereotyping. Therefore, planning authorities should in the long term become more sensitive to issues of ethnic diversity when addressing other specific societal or age groups (teenagers, children, adults, senior citizens).

Our results, as well as responses we obtained from planning institutions, confirm what has been proposed in other studies (Byrne et al. 2009; Leikkilä et al. 2013): that counteracting institutional discrimination as well as promoting positive public opinion about immigrant groups are essential for enhancing the diversity of visitors to parks and for increasing participation in outdoor recreation. Activities on the part of management authorities to identify and sensitively address ethnic communities as target groups can be an important first step in improving integration processes and reducing institutional discrimination.

The generalizability of our findings is limited in so far as people from only two ethnic communities were interviewed. Including a reference-group sample in future research would allow deeper understanding of how visits to and use of parks by ethnic communities differ from those of the mainstream population so that specific access-barriers can be identified.

\section{Acknowledgements}

The project Attitudes and satisfaction of ethnic groups regarding the Wienerwald Biosphere Park: a pilot study towards the integrative function of peri-urban protected areas at the University of Natural Resources and Life Sciences Vienna (BOKU) was funded by the UNESCO Man and the Biosphere research programme of the Austrian Academy of Sciences.

The authors would like to thank all interview partners for their participation, and the management of the Wienerwald Biosphere Reserve for their cooperation and support.

\section{References}

Aizlewood, A., P. Bevelander \& R. Pendakur 2006. Recreational participation among ethnic minorities and immigrants in Canada and the Netherlands. Journal of Immigrant and Refugee Services 4(3): 1-32. https://doi. org/10.1300/J500v04n03_01

Barton, J. \& J. Pretty 2010. What is the Best Dose of Nature and Green Exercise for Improving Mental Health? A Multi-Study Analysis. Environmental Science \& Technology 44(10): 3947-3955. https://doi. org/10.1021/es903183r

Bauer, N. 2010. Health and recreation in forest and landscape - a retrospective. Schweizerische Zeitschrift für Forstwesen 161(3): 120-125. https://doi.org/10.3188/ szf.2010.0120

Buijs, A.E. 2009. Lay people's image of nature: Comprehensive frameworks of values, beliefs, and value orientations. Society and Natural Resources 22: 417 432.

Byrne, J., J. Wolch \& J. Zhang 2009. Planning for environmental justice in an urban national park. Journal of Environmental Planning and Management 52(3): 365392. https://doi.org/10.1080/09640560802703256

EUMC 2006. Muslims in the European Union. Discrimination and Islamophobia. Available at: http:// fra.europa.eu/sites/default/files/fra_uploads/156Manifestations_EN.pdf (accessed: 30/10/2014)

Floyd, M.F., J.H. Gramann \& R. Saenz 1993. Ethnic factors and the use of public outdoor recreation areas: The case of Mexican Americans. Leisure Sciences 15(2): 83-98. https://doi.org/10.1080/01490409309513190

Gentin, S. 2011. Outdoor recreation and ethnicity in Europe - A review. Urban Forestry \& Urban Greening 10(3): 153-161. https://doi.org/10.1016/j. ufug.2011.05.002

Guite, H.F., C. Clark \& G. Ackrill 2006. The impact of the physical and urban environment on mental well-being. Public Health 120(12): 1117-1126. https:// doi.org/10.1016/j.puhe.2006.10.005

Hartig, T. 2008. Green space, psychological restoration, and health inequality. The Lancet 372(9650): 1614-1615. https://doi.org/10.1016/ S0140-6736(08)61669-4 
Höglhammer, A., A. Muhar \& T. Schauppenlehner 2015a. Outdoor recreation of Turkish immigrants in the Wienerwald Biosphere Park, Austria: A stakeholder process to identify research questions. In: Bruns, D., O. Kühne, S. Theile \& A. Schönwald (eds.), Landscape Culture - Culturing Landscapes. The Differentiated Construction of Landscapes: 129-140. Wiesbaden.

Höglhammer, A., P. Stokowski, A. Muhar, T. Schauppenlehner, E. Yalcintepe \& J. Renner 2015b. Experiences and meanings of leisure for members of the Turkish and Chinese communities in Vienna, Austria. World Leisure Journal 57(3): 196-208. https://doi. org/10.1080/16078055.2015.1066602

Jay, M., K. Peters, A.E. Buijs, S. Gentin, M.E. Kloek \& L. O’Brien 2012. Towards access for all? Policy and research on access of ethnic minority groups to natural areas in four European countries. Forest Policy and Economics 19: 4-11. https://doi.org/10.1016/j. forpol.2011.12.008

Jay, M. \& U. Schraml 2009. Understanding the role of urban forests for migrants - uses, perception and integrative potential. Urban Forestry \& Urban Greening 8(4): 283-294. https://doi.org/10.1016/j. ufug.2009.07.003

Kloek, M.E., A. Buijs, J.J. Boersema \& M.G.C. Schouten 2013. Crossing Borders: Review of Concepts and Approaches in Research on Greenspace, Immigration and Society in Northwest European Countries. Landscape Research 38(1): 117-140. https:// doi.org/10.1080/01426397.2012.690861

Leikkilä, J., M. Faehnle \& M. Galanakis 2013. Promoting interculturalism by planning of urban nature. Urban Forestry \& Urban Greening 12(2): 183190. https://doi.org/10.1016/j.ufug.2013.02.002

Miles, M.B. \& A.M. Huberman 1994. Qualitative Data Analysis: An Expanded Sourcebook. 2nd ed. Thousand Oaks.

Morris, J. \& E. O’Brien 2011. Encouraging healthy outdoor activity amongst underrepresented groups: An evaluation of the Active England woodland projects. Urban Forestry \& Urban Greening 10(4): 323-333. https://doi.org/10.1016/j.ufug.2011.05.006

Nutsford, D., A.L. Pearson \& S. Kingham 2013. An ecological study investigating the association between access to urban green space and mental health. Public Health 127(11): 1005-1011. doi:10.1016/j. puhe.2013.08.016.

O’Brien, L. \& J. Morris 2013. Well-being for all? The social distribution of benefits gained from woodlands and forests in Britain. Local Environment. 356383. https://doi.org/10.1080/13549839.2013.790354

Schnell, P. 2014. Educational mobility of second-generation turks: cross-national perspectives.
Spracklen, K. 2013. Whiteness and Leisure.

Statistik Austria 2014. Migration und Integration. Zablen. Daten. Indikatoren 2014. Available at: https:// www.integrationsfonds.at/fileadmin/content/ Statistisches_Jahrbuch_2014.pdf (accessed: $01 / 11 / 2018)$

Stodolska, M. 2000. Changes in Leisure Participation Patterns After Immigration. Leisure Sciences 22(1): 39-63. https://doi.org/10.1080/014904000272966

Swanwick, C., N. Dunnett \& H. Woolley 2003. Nature, role and value of green space in towns and cities: An overview. Built Environment 29(2): 94-106. https:/ / doi.org/10.2148/benv.29.2.94.54467

\section{Authors}

Anna Höglhammer - corresponing author ${ }^{1}$

holds a PhD from the University of Natural Resources and Life Sciences in Vienna, Austria. Her research focus is on outdoor recreation in urban and peri-urban green areas, including its sociological aspects and user groups (especially immigrants and adolescents), landscape perceptions, and qualitative research methods. E-mail: anna.hoeglhammer@gmx.at

\section{Andreas Muhar ${ }^{1}$}

is a landscape planner and Professor in Sustainable Landscape Development, Transdisciplinarity and Knowledge Integration at the University of Natural Resources and Life Sciences in Vienna, Austria. His current research focuses are the organization of transdisciplinary processes, sustainability transition, and concepts of the relationships between humans and nature. E-mail: andreas.muhar@boku.ac.at

\section{Patricia Stokowski ${ }^{1,2}$}

is a Professor at the Rubenstein School of Environment and Natural Resources, University of Vermont, USA. She conducts research into social, cultural and discursive aspects of outdoor recreation behaviour, environmental interpretation, and tourism development in rural and resource-dependent communities. E-mail: patricia.stokowski@uvm.edu

1 Institute of Landscape Development, Recreation and Conservation Planning, University of Natural Resources and Life Sciences, Peter Jordan-Str. 82, 1190 Vienna, Austria.

${ }^{2}$ Rubenstein School of Environment and Natural Resources, University of Vermont, Burlington, USA. 